\title{
A Case Study of an Inclusive Museum: The National Archaeological Museum of Cagliari Becomes "Liquid"
}

\author{
Anna Maria Marras, Maria Gerolama Messina, Donatella Mureddu, \\ and Elena Romoli
}

\begin{abstract}
From 6 to 20 June 2014, the General Directorate for the Promotion of Cultural Heritage of Ministry of Cultural Heritage and Activities and Tourism (MIBACT) launched the online consultation \#culturasenzaostacoli in order to financially support a project for museum accessibility. The National Archaeological Museum of Cagliari received the most votes. Since then the museum's team started working on the project that was called "liquid museum", mainly due to its aims of adaptability and inclusivity. This article describes the project and the main guidelines that led to the draft currently being developed. Issues related to the new exhibition and multimedia displays will not be addressed herein. The focus of this document is the new approach in the writing of a project that is not only easily replicable but especially sustainable over time, both in terms of economic costs and for the technologies that it uses, and thus ready to be changed, updated when necessary, and because of this 'liquid'.
\end{abstract}

\section{Introduction}

A museum is a non-profit, permanent institution in the service of society and its development, open to the public, which acquires, conserves, researches, communicates and exhibits

\footnotetext{
A.M. Marras $(\triangle)$

Digital Heritage Consultant

e-mail: am.marras@gmail.com

M.G. Messina • E. Romoli

Archaeological Superintendence of Sardinia, Sardinia, Italy

e-mail: mariagerolama.messina@beniculturali.it; elena.romoli@beniculturali.it

D. Mureddu

Museums of Sardinia, Sardinia, Italy

e-mail: donatella.mureddu@beniculrturali.it

(C) The Author(s) 2016

K.J. Borowiecki et al. (eds.), Cultural Heritage in a Changing World,

DOI 10.1007/978-3-319-29544-2_6
} 
the tangible and intangible heritage of humanity and its environment for the purposes of education, study and enjoyment (ICOM 2015). ${ }^{1}$

With this powerful definition in its statute the International Council of Museums (ICOM) defines what a museum is. Among other aspects, we would stress that museums are seen as institutions at the service of society as a whole and exist for its development. Therefore, museums are no longer wuderkammer, cabinets of wonders, but ever changing places that have an active role in society, of which they are, in many ways, an expression (JALLA 2003: 249). In addition to being an institution at the service of society, museums can be defined as such if they are open to the public, and therefore accessible to everyone. The concept of accessibility comes in varying degrees and forms and for some time now is associated with the idea of inclusiveness, because the visit must be lived without barriers and differences, allowing everyone to access the available contents and information.

\section{The Contest \#Culturasenzaostacoli}

From 6 to 20 June 2014, the General Directorate for the Promotion of Cultural Heritage of MIBACT launched the online consultation \#culturasenzaostacoli (MIBACT 2014). Funding for the construction of an accessibility route was the prize for the selected museums. The National Archaeological Museum of Cagliari (MARC), which had been included as one of the 17 museums selected for the consultation, received the most votes.

This exceptional result was due to the collective effort of the employees of the Superintendence for the Archaeological Heritage of the Provinces of Cagliari and Oristano, the support of local associations, and the support of the famous jazz musician Paolo Fresu, who supported the museum with his testimonial. The campaign slogan, 'At MARC, music will be the same for all' was based on an idea by director Donatella Mureddu.

A key role was played by online communication, thanks to the hard work of the MARC social media and communication team. Starting in December 2013, in fact, MARC, alongside the National Archaeological Museum of Florence (Archeotoscana blog 2015) is one of the first Italian public museums to have hired an editorial team who specifically works on online communication and runs the MARC blog (Museoarcheocagliari blog 2015) and all museum's social networks accounts (namely Facebook, Twitter and Pinterest, which is actually the less used of the three). The presence of this team was essential to the project's success.

\footnotetext{
${ }^{1}$ ICOM Statutes, at the 21st General Conference in Vienna.
} 


\title{
3 The National Archaeological Museum of Cagliari
}

The National Archaeological Museum of Cagliari is the most important and prestigious institution of archaeology and history of Sardinia. The first collections date back to the nineteenth century, when knight Leonardo de Pruner, under Ludovico Baylle's supervision, set up a room in the Viceregal palace to become the 'Cabinet of Archaeology and Natural History'. Since 1993, the museum is located inside the Citadel of Museums, inside one of the buildings designed by Pietro Gazzola and Libero Cecchini in the 1950s and finished at the end of the 1970s. The museum is rather large, arranged around an atrium, on four floors. Being on the highest hill in town, through its wide windows and balconies it offers visitor a beautiful view of Cagliari from above. The permanent exhibition of MARC includes over three thousand artefacts which are important for the understanding of the history and the culture of Sardinia as well as those concerning past civilizations living and thriving around the Mediterranean sea.

The archaeological collection is arranged over three floors. It follows a chronological order at first, then a topographic order. The first floor is largely devoted to a narration of the historical and archaeological development of Cagliari, and the second floor displays findings from some of the most ancient settlements and town of Sardinia (such as Nora, Bithia, Monte Sirai, Sant'Antioco). The third floor is for temporary exhibitions, and it currently hosts the exhibition 'Mont'e Prama 1974-2014', which, for the first time after the restoration, showcases the famous Mont'e Prama sculptures, extraordinary and unique examples of monumental statuary from the Nuragic period (Iron age) of Sardinia. The exhibition is also at the local museum of Cabras G. Marongiu.

\section{$4 \quad$ Liquid Museum: A Moving Museum}

\begin{abstract}
"Alongside the duty of preserving its heritage, every museum aims at making it accessible to different and diverse audiences, enabling its use for education, culture, diversion and more. Interpreting its own heritage and making it accessible to all visitors, especially by displaying it, is therefore an integral part of museums' raison d'être" (MIBACT 2001). ${ }^{2}$
\end{abstract}

Based on this definition, the accessibility project led by MARC called 'Liquid Museum' was born. The word 'liquid' does not mean 'fragile' and 'elusive' as it does in the Bauman theory (Bauman 2000); instead it means 'mobile', as in ready to receive new content. At the same time the technologies used are not fixed, but they are ready to adapt and change. 'Liquid' suggest a museum for children, the elderly, foreigners, the disabled, and is thus chameleon-like, a museum that can take different shapes and sizes to suit the needs of any visitor.

The liquid museum is accomplished through the building of perceptual and sensory pathways that allow a total use of the museal structure and its contents,

\footnotetext{
${ }^{2}$ Ministry of National Heritage and Culture decree of 10 May 2001, precondition VII.
} 
because "art, in all its manifestations, is a language and therefore a form of communication. As communicative act it should be affordable and accessible to all" (Addis 2002: 35). During the time of the project the museum will become a liquid empathic museum that is able to understand the needs of its visitors and to adjust and adapt its contents. This will be accomplished through social networks and periodic surveys designed to explore what the visitors would like of their museum and how they feel when visiting it. Moreover the museum staff, thanks a proper welcome training, will be able to better support the visitors needs and emotions. Visitor emotion and feeling is an important focus of museums, as it is exemplified by the Empathy Museum (2015), that will be opened in London and whose aim is to stimulate empathy between people.

An archaeological museum is by its nature a container full of objects that explain gestures and rituals of the past. These items often have unusual shapes and curious sounding names that are sometimes difficult to understand or even remember for non-specialists. Archaeological artefacts carry with them a set of historical, typological and functional information that need to be communicated and shared with the public in a simple but not prosaic language. Technology and a new way of communicating history are essential to this, especially to make content accessible to people with cognitive disabilities.

For a long time it was thought that the removal of physical barriers and the creation of tactile paths were the best way to make museums accessible. Nowadays, the approach is different (Gilli and Rozzi 2013), and attention is also paid to learning disabilities (such as autism and others). Here the focus is shifting from what is displayed to the way it is displayed and the textual-communicative apparatus that goes along with it (Museoarcheocagliari blog 2015). Small but important expedients are the use of Sans Serif fonts, the right distance between text lines and an appropriately coloured background. Moreover, a simplified but not trivialized rhetoric is implemented, which helps explain the significance of the artefacts themselves, their use in ancient times and their role within the scenario that is set up in the exhibition. Therefore artefacts must be understandable for children, teen agers, the elderly and families with children.

This revolution is a 'new' way of seeing museums as a space for social integration. This includes the importance of migrant integration such as the Museum of the City of Liverpool and the European Museums in an Age of Migrations project (MeLa Project 2015), funded by the European Commission, which aims to

"delineate new approaches for museums in relation with the conditions posed by the migrations of people, cultures, ideas, information and knowledge in the global world. Its main objectives are to advance knowledge in the field and to support museum communities, practitioners, experts and policymakers in developing new missions and forms of museums and libraries in "an age of migrations." (MELA website)

In order to facilitate adaptation and renewal of exhibitions and visitors' engagement, museums should not be static. Instead of setting up new showcases (which MARC already has) the use of apps and innovative multimedia displays was preferred, all of them adaptable, so that everyone can benefit from a visit that is 
accessible to all and thus shared. Multimedia displays will thus be designed in such a way that they are easily adaptable and renewable for new productions, new paths and new exhibition themes, and of course adaptable to include new findings and artefacts, because the MARC must be able to update its contents without losing its accessibility.

In addition to that, the museum staff will provide engaging guided tours, in order to receive visitors in the best possible way and enhance their enjoinment of MARC. Human contact, in fact, is not only complementary to multimedia devices, but essential to accessibility. The museum must be accessible from the moment it is entered and for that reason all staff member should be trained and prepared to offer the utmost welcome to all their visitors. The entire exhibition route inside the MARC will be revised and designed in such a way as to allow an independent and varied realisation of the museum's collections, and in doing so for instance, well known deterrents for disabled participation will be overcome. In this new blueprint, all the exhibition panels will be revised to follow the new design rules (e.g. using left alignment text, using proper colours, simplifying text, using multimedia support). We will organize a monthly meeting with associations inside the museum and co-organize special 'accessibility day' in order to stimulate the meeting between associations and citizens in order to transform the museum as a social space.

Unfortunately material limits and economic issues prevent MARC from undergoing architectural changes, nevertheless the collections contents (description objects, multimedia) will be updated, integrated and made accessible to all. Visitors, real or virtual ones, should have access to the contents and information that allow them to experience museums in a very personal way, but also to share contents, comments and photos with others visitors. For that reason, our project adopts the definition of a museum that can be found in the Act of Address Museums by ICOM which was included in the Art Bonus Decree (Decree 83/2014). It states that a museum is a civic and social space. This was also supported by the online course given at Leicester University entitled 'Behind the scenes at the 21th Century Museum' that also aimed for a new information and communication strategy in museums.

\subsection{A New Meaning of Museum Accessibility}

As already mentioned, in the past the term 'museum' generally meant a set of arranged spatial features, which created an area that was autonomous and easy for everyone to access, included disabled people. The Liquid Museum project follows the instructions drawn from the Design For All project (Acolla 2009) and the MARC is committed to addressing the key points given by the Italian Ministry regarding accessibility which include: orientation, reference points, signage, maps, overcoming distances, overcoming of differences in height, and equipment such as ramps. The innovation in the accessibility concept is strictly related to the content 
of the museum, without forgetting the importance of breaking down architectural barriers, through many different aspects, which include:

- Physical. Removal of physical barriers.

- Sensorial. Visitors are given a chance to touch some original findings and/or 3D models (Zimmer 2008) that were made during teaching-learning sessions planned in the museum, in and CRS4 collaboration with Sardinia Research Center Fablab (Fablab Sardegna Ricerche 2015). The experience of being able to touch the objects or their reproductions is perhaps one of the most low-cost solutions, and makes the museum more accessible and friendly to visitors. These experiences always encourage more than one visit, as witnessed in the exhibition Tate Sensorium at the Tate Britain in London which offered visitors a chance to experience a museum that stimulates the hearing, smell, taste, touch (Tate Museum 2015). The Prado Museum recently has carried out 3D copies of some masterpieces, in order to make them touchable for visitors (MUSEO PRADO). In Italy, for several years, the National Tactile Museum Omero (Omero Museum 2015) has, as its mission, not only offered a touchable museum, but in its rooms there are the reproductions of some of the most important masterpieces of Italian cultural heritage. Their interest is also to provide support to institutions to organize a tactile or sensorial pathway.

- Digital. Generally the Information and communications technologies (ICT) are considered an important support in the management and use of contents both of the museum staff and visitors. Two case studies carried out by the European project The Learning Museum (LEM Project) shows that multimedia has to be well-built, with attention not only to the quality of the content (texts, images) but also the usability of instruments and their playful aspect. For the museum's Liquid Project, the artefacts will first be digitised by using different techniques (photomodelling, lasercan), and then 3D models will be created. Both processes are planned as a training activity open and free not only for the museum staff but also for students. The new technologies of digitalization applied to the museum context furthermore encourage the enjoyment of the collection via remote access. Recently, the British Museum added downloadable 3D models of its collections in the Sketchfab (2015) platform, under the CC-BY-SA (attribution + sharealike) user licence. This is undoubtedly an important step that confirms that museums who make their collections accessible online do not risk having fewer visitors and in fact increase the visibility of the museum itself. This is evident in the increasing number of museums on the Google Art project of the Google Cultural Institute (Google Art Project 2015), where there are photo galleries of 596 museum collections. Data associated with these collections are often open or downloaded directly from the site as open data (e.g. GITHUB MOMA). The most important reference regarding open access is given by the Open GLAM (Galleries, Libraries, Archives and Museums) project by the Open Knowledge Foundation (OpenGLAM 2015) and the GLAM project supported by the Wikimedia Foundation (GLAM 2015), where once again the British Museum is involved (GLAM British Museum 2015). These projects are 
designed to give support to institutions in the form of procedures for sharing information such as mainly metadata and images of their objects. Starting with these examples, a key aspect of the Liquid Museum, after digitization, is the creation of the museum's website and its Digital Library (DL). The website, built with free Content Management System (CMS) software and according to the usability standards of W3C will be handled by specially trained museum staff, and will be designed as a real museum guide. Through systems such as Quick Response Code (QR) and Near Field Communication (NFC) the user may download and/or view the contents (video guides, images, insights) that help in the exploration of collections. Museum tours will be possible through a web-based geographical information system (Indoor WebGIS) able to help the visitor to discover museum paths and collections. A second WebGIS based on Openstreetmap $\mathrm{API}^{3}$ will be built in order to visualize and to research the archaeological sites whose findings and/or contexts are present in the museum.

The most important objects will have navigable online three-dimensional models, in addition to images. The blog of the museum will be integrated into the website to allow interaction with users-visitors. Metrics will be used to evaluate the performance and user interaction with the site content. Fundamental to the process is the how the exhibits impart knowledge, which is why the site will include a digital library of museum exhibits. The creation of the digital library of artefacts and sites will prepare for data acquisition (photos, video) that will be carried out by the museum staff. The museum currently has a database of findings in FileMaker 12, made during a program called Master and Back funded by Autonomous Region of Sardinia. During this project and thanks to co-financing supported from Autonomous Region of Sardinia and Superintendence for Archaeological Heritage of the Provinces of Cagliari and Oristano, ${ }^{4}$ three fellows have been employed for 2 years (from 2012 to 2014) at the MARC: the restorer Maura Mereu and the archaeologists, Enrico Trudu and Anna Maria Marras, who designed the database and wrote the users guideline. This database will be imported into the new database online, which will be implemented with open source software, following the Italian National Institute for Cataloguing (ICCD) guidelines and using metadata schema of Europeana (EUROPEANA 2015) in order to facilitate dialogue and integration with both systems. Datasets of the collections will be dowloadable as open data from a section of the website, following the example of the Fondazione Torino Musei that, on the occasion of the Open Data day of 2014, has made this information available (Fondazione Torino Musei 2014)

- Training. Training is a key element for the accessibility of the project, which goes hand in hand with the web site creation, the new exhibition itinerary and the carrying out of multimedia solutions. Over the course of the project, several

\footnotetext{
${ }^{3}$ Open Street Map (OSM) is a collaborative project born in 2004 to create a free editable map. OSM is use also for indoor mapping.

${ }^{4}$ http://www.archeocaor.beniculturali.it
} 
different training sessions will be implemented aimed at improving how visitors are greeted, the abilities of the staff, and the expertise in using the different devices. In order to improve the knowledge of English, courses such as those provided by Massive Open Online Courses (MOOC) are to be held at the Museum. In order to enhance visitor reception a course called "Welcome and Smile" will be given by experts in the field. As already mentioned, in order to allow the museum staff to update their digital content in real time, training sessions for "digital acquisition objects" will be given and, moreover, the Museum will purchase a small laser scanner for surveys of small objects. Another training course will be given on the reproduction of $3 \mathrm{D}$ objects in collaboration with the FabLab of Sardinia Research and its makers and will be opened to students. Some workshops will also be planned in collaboration with citizens' associations in order to enhance the spirit of sharing and participation that is the main goal of the Liquid Museum.

\subsection{Technologies as Liquid Tools}

Nowadays the importance of technology in cultural enjoyment is acknowledged and generally accepted. Technology is changing the way we think about museums (Levent et al. 2014). Being a trusted public space and a trusted source of information, museums have a potential to transform those technologies used elsewhere for commercial and surveillance purposes. Technologies, on the other hand, might have the potential to aid museums in redefining their unique place in public life (Levent et al. 2014). Technology is changing the relationship between the public and a museum object (Levent et al. 2014). Technology is more and more present in museums, helping develop new ways to enhance the enjoyment of the visit and providing the means to be more inclusive, like 3D, immersive technologies, augmented reality, video reconstructions and simulations. The relatively low cost and the use of open source software makes it easier for museums to use new technologies.

A critical issue, however, is the lack of sustainability (the importance of the term of sustainanbility is well explained in Pilotti 2003) for some of these technological tools and the difficulty in keeping up with the rapid evolution of technology. Unfortunately, even the most new and innovative app will become obsolete in a very short time, and visitors, who are very often conscious consumers of hi-tech software and devices, are left bored with museums that are filled with old equipment and/or computer screens that are no longer useful. To counter act this, we will use open source technologies, that can be sustained for longer and allow for constant maintenance and updating. At the same time, open formats for data and international standards for metadata will be used as open formats promote an easier re-use of information in different apps. 


\subsection{A Network for an Open Museum}

Liquid museum is a museum without barriers. It is a museum that seeks a dialogue with its visitors and with other agencies to ensure that the project involves not only the entire City of Cagliari but also all Sardinia region. The museum must be connected with other museums. In order to facilitate this process, the international museum communities are improving their networks not only in terms of thematic but on digital and accessibility issues (e.g. NEMO and Museomix 2015). The plan for dissemination foresees that the project will be presented through the social network of the museum and the creation of a section of the blog which will be dedicated to the project and includes all activities related to teaching and training. Before any activity starts, however, the museum needs to better know, also through surveys, its audiences. The knowledge of both the museum visitors and the online museum visitors are important in order to understand who they are and how they support the museum's reputation.

Another Liquid Museum activity is the installation of book-crossing library inside the museum with publications on Sardinian archaeology, in this way the museum reaffirms once again its social role and the deep connection with the territory and the town.

\section{Conclusion}

In recent years the technologies applied to cultural heritage have become more and more accessible. The "open source revolution" has helped museums not only with lower production costs, but also, with access to open data. In the introduction to this chapter, we used the definition of 'museum' as is written in the International Council of Museums (ICOM) statutes, highlighting the role of museum as an institution in the 'service of society' and open to all. In drawing up the plan for our museum it was very important to highlight another aspect also written in ICOM definition, which is the 'educational role' of the museum.

Finally, if the project's main goal is to have a fully inclusive museum, it is necessary to better interpret several point of views and issues, to articulate and separate the different activities designed according to the different types of accessibility. These accessibility types are: physical, cognitive, sensory and also, for the first time involves the issue of digital accessibility. The latter is more important for the future of the museum and for the museum of the future, not only in order to promote online access to museum collections, but above all for a smart use of new technologies, able to support both archiving and the dissemination of information about museum's objects.

Open Access This chapter is distributed under the terms of the Creative Commons AttributionNoncommercial 2.5 License (http://creativecommons.org/licenses/by-nc/2.5/) which permits any noncommercial use, distribution, and reproduction in any medium, provided the original author(s) and source are credited. 
The images or other third party material in this chapter are included in the work's Creative Commons license, unless indicated otherwise in the credit line; if such material is not included in the work's Creative Commons license and the respective action is not permitted by statutory regulation, users will need to obtain permission from the license holder to duplicate, adapt or reproduce the material.

\section{References}

Acolla, A. (2009). Design for all. Il progetto per l'individuo reale. Milano: FrancoAngeliAddis.

Addis, M. (2002). Nuove tecnologie e consumo di prodotti artistici e culturali: Verso l'edutainment. Micro \& Macro Marketing, 11(1), 33-59.

Bauman, Z. (2000). Liquid modernity. Cambridge, England: Polity.

Gilli, G., \& Rozzi, F. (2013). Smart museum. La psicologia della fruizione artistica. Milano: Franco Angeli.

ICOM. (2015). Retrieved from http://icom.museum/the-vision/museum-definition/.

Jalla, D. (2003). Il museo contemporaneo. Introduzione al nuovo sistema museale italiano. Torino, Italy: Utet.

Levent, N., Knight, H., Chan, S., \& Hammer, R. L. (2014). Technology, senses, and the future of museums. In N. Levent \& A. Pascual-Leone (Eds.), The multisensory museum, crossdisciplinary perspectives on touch, sound, smell, memory, and space (pp. 341-348). Lanham, MD: Rowman \& Littlefield.

MIBACT. (2001). Retrieved from http://www.beniculturali.it/mibac/multimedia/MiBAC/ documents/1310746917330_DM10_5_01.pdf.

Pilotti, L. (2003). Conoscere l'arte per conoscere. Marketing, identità e creatività delle risorse culturali verso ecologie del valore per la sostenibilità. Padova, Italy: Cedam.

Settis, S. (2002). L'illusione dei beni digitali. In Bollettino ICR: Nuova Serie (n. 5, pp. 18-20). Roma.

Zimmer, R. (2008). Touch technologies and museum access. In H. Chatterjee (Ed.), Touch in museums: Policy and practice in object handling (pp. 150-162). Oxford, England: Berg.

\section{Websites}

Archaeological Superintendence of Sardinia. (2015). http://www.archeocaor.beniculturali.it

Archeotoscana blog. (2015). Retrieved November 13, from www.archeotoscana.wordpress.com

Behind the Scenes at the 21st Century Museum. (2015). Retrieved November 13, from https://le. ac.uk/courses/mooc-behind-the-scenes-at-the-21st-century-museum

Empathy Museum. (2015). Retrieved November 15, from http://www.empathymuseum.com

Europeana. (2015). Retrieved November 15, from http://pro.europeana.eu/share-your-data/

Fablab Sardegna Ricerche. (2015). Retrieved November 9, from http://www.sardegnaricerche.it/ fablab/

Fondazione Torino Musei. (2014). Opendata. Retrieved November 15, from http://opendata. fondazionetorinomusei.it

GLAM. (2015). Retrieved November 15, from https://en.wikipedia.org/wiki/Wikipedia:GLAM

GLAM British Museum. (2015). Retrieved November 15, from https://en.wikipedia.org/wiki/ Wikipedia:GLAM/British_Museum

Google Art Project. (2015). Retrieved November 15, from https://www.google.com/ culturalinstitute/project/art-project?hl=it

ICCD. (2015). Retrieved November 15, from http://www.iccd.beniculturali.it 
LEM The Learning Museum. (2015). Retrieved November 15, from http://ibc.regione.emiliaromagna.it/en/the-institute/european-projects-1/lem

Liverpool Museum. (2015). Retrieved November 15, from http://www.liverpoolmuseums.org.uk/ mol/index.aspx

Mela Project. (2015). Retrieved November 13, from http://www.mela-project.eu, http://www. mela-project.eu

MIBAC website. (2015). http://www.beniculturali.it/mibac/export/MiBAC/sito-MiBAC/Contenuti/ MibacUnif/Comunicati/visualizza_asset.html_727607053.html

MIBACT. (2014). Cultura senza ostacoli. Retrieved June 6, from http://www.beniculturali.it/ mibac/export/MiBAC/sito-MiBAC/Contenuti/MibacUnif/Comunicati/visualizza_asset.html_ 727607053.html

MOMA Github. (2015). Retrieved August 13, from https://github.com/MuseumofModernArt/ collection

Musei Senza Barriere. (2014). Retrieved January 9, from http://museisenzabarriere.org/

Museoarcheocagliari blog. (2015). Retrieved September 23, from https://museoarcheocagliari. wordpress.com

Museomix. (2015). Retrieved November 10, from http://www.museomix.org

Near Field Communication. (2015). https://it.wikipedia.org/wiki/Codice_QR; https://it.wikipedia. org/wiki/Near_Field_Communication

Nemo Project. (2015). Retrieved November 10, from http://www.ne-mo.org/about-us/the-lemnetwork.html

Omero Museum. (2015). Retrieved November 9, from http://museoomero.it

OpenGLAM. (2015). Retrieved November 9, from http://openglam.org

OpenStreetMap. (2015). http://wiki.openstreetmap.org/wiki/Indoor_Mapping

OpenStreetMap indoor tool mapping. (2015). http://osmtools.org

Prado Museum. (2015). Retrieved November 9, from https://www.museodelprado.es/en/ exhibitions/exhibitions/at-the-museum/hoy-toca-prado/

Sketchfab. (2015). Retrieved November10, from https://sketchfab.com

Tate Museum. (2015). Tate sensorium. Retrieved November 9, from http://www.tate.org.uk/ whats-on/tate-britain/display/ik-prize-2015-tate-sensorium

W3C. (2015). Retrieved November 9, from http://www.w3.org 